\title{
Photo-anthropometric study on face among Garo adult females of Bangladesh
}

\author{
Akhter $\mathrm{Z}^{1}$, Banu MLA², Alam MM³ , Hossain $\mathrm{S}^{4}$, Nazneen $\mathrm{M}^{5}$ \\ ${ }^{I}$ Department of Anatomy, Dhaka Central International Medical College \& Hospital, ${ }^{2}$ Department of Genetic \& \\ Molecular Biology, Bangabandhu Sheikh Mujib Medical University, Dhaka, ${ }^{3}$ Department of ENT \& Head Neck, \\ Shahid Sohrawardy Medical College, Dhaka, ${ }^{4}$ Department of Anatomy, Green Life Medical College and Hospital, \\ Dhaka, ${ }^{5}$ Department of Biochemistry, Dhaka Central International Medical College, Dhaka. \\ Email: mayesha2010@yahoo.com
}

\begin{abstract}
Facial anthropometry has well-known implications in health-related fields. Measurement of human face is used in identification of person in Forensic medicine, Plastic surgery, Orthodontics, Archeology, Hairstyle design and examination of the differences between races and ethnicities. Facial anthropometry provides an indication of the variations in facial shape in a specified population. Bangladesh harbours many cultures and people of different races because of the colonial rules of the past regimes. Standards based on ethnic or racial data are desirable because these standards reflect the potentially different patterns of craniofacial growth resulting from racial, ethnic and sexual differences. In the above context, the present study was attempted to establish ethnic specific anthropometric data for the Christian Garo adult females of Bangladesh. The study was an observational, cross-sectional and primarily descriptive in nature with some analytical components and it was carried out with a total number of 100 Christian Garo adult females aged between 25-45 years. Three vertical facial dimensions such as facial height from 'trichion' to 'gnathion', nasal length and total vermilion height were measured by photographic method. Though these measurements were taken by photographic method but they were converted into actual size using one of the physically measured variables between two angles of the mouth (chilion to chilion). The data were then statistically analyzed by computation to find out its normatic value. The study also observed the possible 'correlation' between the facial height from 'trichion' to 'gnathion' with nasal length and total vermilion height. Multiplication factors were estimated for estimating facial height from nasal length and total vermilion height. Comparison were made between 'estimated' values with the 'measured' values by using ' $t$ ' test. The mean $( \pm \mathrm{SD})$ of nasal length and total vermilion height were $4.53 \pm 0.36 \mathrm{~cm}$ and $1.63 \pm 0.23$ $\mathrm{cm}$ respectively and the mean $( \pm \mathrm{SD})$ of facial height from 'trichion' to 'gnathion' was $16.88 \pm 1.11 \mathrm{~cm}$. Nasal length and total vermilion height showed also a significant positive correlation with facial height from 'trichion' to 'gnathion'. No significant difference was found between the 'measured' and 'estimated' facial height from 'trichion' to 'gnathion' for nasal length and total vermilion height.
\end{abstract}

\section{Introduction}

An important phenomenon occurring in human population is the variation in their physical morphology. The physical dimensions of human body are influenced by ecological, geographical, racial, age and gender factors ${ }^{1}$. Anthropometry plays an important role in distinguishing a pure race from the local mingling of races ${ }^{2}$. Anthropometry is a series of systematized measuring techniques that expresses quantitatively the dimensions of the human body and skeleton ${ }^{3}$. Cephalometry is one of the important parts of anthropometry in which the dimensions of head and face are measured ${ }^{4}$. A primary characteristic by which humans present themselves to the external world is via the anatomy of their facial shape ${ }^{5}$. Anthropometric measurements are important in finding out of a person in any accidental case like road traffic accident, earth quack, burn, natural disaster, plane crash etc ${ }^{6}$. Cephalometric results are used in forensic medicine, plastic surgery, oral surgery, pediatrics, dentistry and diagnostic knowledge between patient and normal population ${ }^{4}$. In addition to these for treating congenital or post traumatic facial disfigurements, surgeons require access to craniofacial data based on accurate anthropometric measurements ${ }^{7}$. Therefore knowledge of the anthropometric and cephalometric measurements are essential before planning surgical treatment ${ }^{7}$. Though work concerning estimation of stature from long bone as well as from certain body dimensions have been put forward for some of the Bengali populations but research concerning estimation of facial height from 'trichion' to 'gnathion' from other vertical small facial dimensions in Bengali females as well as in tribal females is scanty. It is well established that a single standard of facial aesthetics is not appropriate for application to diverse racial and ethnic groups. In Bangladesh studies on craniofacial measurements are limited on caste and community \& are rare in tribal population. Bangladesh is a country not only for the Bengali, there are about 30 tribal communities living at the 
different parts of Bangladesh ${ }^{6}$. They mostly live in Mymensingh, Netrokona, Tangail, Sylhet \& Sunamgonj districts of Bangladesh. They are an ethnic group of 'Tibbeti Borman', belonging to the Mongolian human race. They usually speak in Garo language among themselves, but they know Bangla too. Matriarchal family pattern is usually seen among the Garos. They are different from any other tribal community and of course not consistent with the tradition of mainstream Bangladeshi people ${ }^{8}$.

With above background the present study was conducted with the intention to establish ethnic specific anthropometric data for the Garo populations with specific ethnic background as they have their own set of language, social structure, cultures \& economic activities and religious values.

\section{Materials and Methods}

The study was carried out on 100 Christian Garo adult females. Their age ranged from 25 to 45 years. The study was basically an observational, cross-sectional and primarily descriptive in nature. There was also another analytical procedure used to compare two corresponding sets of data ('measured' and 'estimated' values) for these facial variables. Three vertical facial variables were measured by photographic method such as facial height from 'trichion' to 'gnathion', nasal length and total vermilion height. Though these vertical measurements were taken by photographic method but they were converted into actual size using one of the physically measured variable. Initially each subject was seated comfortably on a chair; the subject's head was at the same level as the camera on camera stand having a distance of 120 centimeter between the two. The subject's face was well illuminated. Before taking photograph of each subject, one physical measurement was taken by a slide caliper between two angles of the mouth (chilion to chilion) ${ }^{9}$. By using this individual physical value, each photograph was converted into actual size. The photographic measurements of the subjects were done by using a computer program named adobe illustrator version-10. The "width of the mouth' of individual photograph was transformed equal to physically measured value ((chilion to chilion) by using the transform option of adobe illustrator and ultimately each photograph was converted into actual size. At first the approximate mid point of the photographic hairline 'trichion' and the chin 'gnathion' were determined. The vertical distance of 'trichion' to 'gnathion' was considered as facial height from 'trichion' to 'gnathion, (Fig: 1) Then the nasal length and total vermilion height of the individual were measured from the photograph. The vertical distance from 'nasion' to 'subnasale' was considered as 'nasal

length ${ }^{\text {10 }}$ (Fig: 2) and vertical distance from midpoint of the labiale superious and midpoint of the labiale inferious was considered as total vermilion height ${ }^{7}$ (Fig 2). By this way all the photographs were measured.

Calculations of multiplication factor: Each 'multiplication factor' is the ratio of the facial height from 'trichion' to 'gnathion' to the nasal length and total vermilion height. Mean multiplication factor ${ }^{10}$ was then calculated for nasal length and total vermilion height. That mean multiplication factor was used for estimating the facial height from 'trichion' to 'gnathion' from nasal length and total vermilion height.

Multiplication factor ${ }^{11}$ (M.F.) of nasal length was calculated using following formula:

M.F = Facial height from 'trichion' to 'gnathion'

Multiplication factor (M.F.) of total vermilion height was also calculated by using above formula.

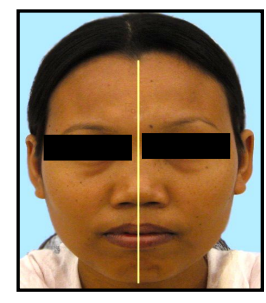

Fig 1: Procedure for measuring facial height from 'trichion' to 'gnathion'

\section{Results}

The mean values and the standard deviations were calculated for three vertical facial variables. These are listed in table-1. Correlations of the photographically-measured nasal length and total vermilion height with facial height from 'trichion' to 'gnathion' were also assessed and the findings are displayed using scatter diagrams. Multiplication factors were calculated for estimating facial height from 'trichion' to 'gnathion' which are also listed in Table-l. The Table-ll shows the effectiveness of the use of the multiplication factors in these estimations were tested by paired' $t$ ' test whether there are significant differences between the 'measured' values and corresponding 'estimated' values. The mean $( \pm \mathrm{SD})$ of facial height from 'trichion' to 'gnathion', nasal length and total vermilion height were respectively $16.88 \pm 1.11$, $4.53 \pm 0.36$ and $1.63 \pm 0.23$. Here nasal length and total vermilion height showed significant positive correlation $(\mathrm{r}=0.685, \mathrm{p}=0.001)(\mathrm{r}=0.359, \mathrm{p}=0.001)$ with facial height from 'trichion' to 'gnathion' (Figure-3 and 4). The mean multiplication factor $( \pm$ SD) for estimating the facial height from 'trichion' to 'gnathion' from nasal length and total 
vermilion height were found as $3.73 \pm 0.22$, and $10.58 \pm 1.56$ respectively (Table-I). For these two vertical facial variables, the measurement in each individual was multiplied by the mean multiplication factor for that variable to get the 'estimated' facial height from 'trichion' to two 'gnathion' for that variable. Then for each of the vertical facial variables the 'measured' and 'estimated' facial height from 'trichion' to 'gnathion' were compared for any significant difference, using the paired ' $t$ ' test. No significant difference was found between the 'measured' and 'estimated' facial height from 'trichion' to 'gnathion' for the nasal length and total vermilion height (Table-II). This indicates the possibility of effectiveness of the corresponding multiplication factor in this estimation.

Table-I: Correlation of nasal length and total vermilion height with facial height obtained through photographic procedure

\begin{tabular}{|c|c|c|c|c|c|c|}
\hline \multirow{2}{*}{ Variables } & \multicolumn{3}{|c|}{ Facial measurement } & \multirow{2}{*}{$\begin{array}{l}\text { Mean } \\
\text { multiplication } \\
\text { factor } \pm \text { SD }\end{array}$} & \multirow{2}{*}{\multicolumn{2}{|c|}{$\begin{array}{l}\text { Significance of correlation with } \\
\text { facial height from trichion to } \\
\text { 'gnathion' }\end{array}$}} \\
\hline & Range(cm) & \multicolumn{2}{|c|}{$\operatorname{Mean}(\mathrm{cm}) \pm \mathrm{SD}$} & & & \\
\hline Facial height from 'trichion' to 'gnathion' & $14.44-20.11$ & \multicolumn{2}{|c|}{$16.88 \pm 1.11$} & & \\
\hline Nasal length. & $3.88-5.65$ & \multicolumn{2}{|c|}{$4.53 \pm 0.36$} & $3.73+0.2$ & \multicolumn{2}{|c|}{$\mathrm{p}=0.001$} \\
\hline Total vermilion height. & $1.10-2.25$ & \multicolumn{2}{|c|}{$1.63 \pm 0.23$} & $10.58+1$. & \multicolumn{2}{|c|}{$\mathrm{p}=0.001$} \\
\hline \multicolumn{7}{|c|}{$\begin{array}{l}\mathbf{n}: 100 \text { for each variable. } \\
\text { Table -II: Comparison between the 'measured' facial height from 'trichion' to 'gnathion' and the facial height from 'trichion' to 'gnathion' } \\
\text { 'estimated' from nasal length and total vermilion height }\end{array}$} \\
\hline \multirow{3}{*}{ Vertical facial variable } & \multirow{2}{*}{\multicolumn{3}{|c|}{$\begin{array}{l}\text { Measured facial height from } \\
\text { 'trichion' to 'gnathion' }\end{array}$}} & \multirow{2}{*}{\multicolumn{2}{|c|}{$\begin{array}{l}\text { Estimated facial height from } \\
\text { 'trichion' to 'gnathion' }\end{array}$}} & \multirow{3}{*}{$\begin{array}{r}\text { Significance of } \\
\text { difference }\end{array}$} \\
\hline & & & & & & \\
\hline & Mean $(\mathrm{cm})$ & \pm & SD & Mean $(\mathrm{cm})$ & SD & \\
\hline Nasal length & 16.88 & \pm & 1.11 & 16.91 & 1.34 & $\mathrm{p}=0.730$ \\
\hline Total vermilion height & 16.88 & \pm & 1.11 & 17. 19 & 2.52 & $\mathrm{p}=0.192$ \\
\hline
\end{tabular}

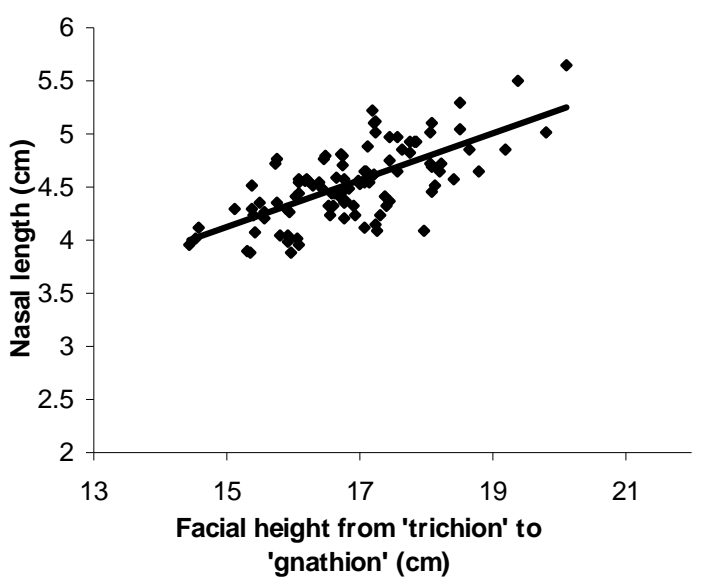

Fig-3: Scatter diagram with regression analysis showing significant positive correlation between the facial height from 'trichion' to 'gnathion' and the nasal length $(\mathrm{r}=0.685, \mathrm{p}=0.001)$.

\section{Discussion}

The present anthropometric study was carried out among Christian Garo adult females with a view to measuring three vertical facial dimensions from photograph such as facial height from 'trichion' to 'gnathion', nasal length and total vermilion height. It also looked for any correlation between facial heights from 'trichion' to 'gnathion' with nasal length and between facial heights from 'trichion' to 'gnathion' with total vermilion height. Estimation of facial height from 'trichion' to 'gnathion' was made from nasal length and total vermilion height using multiplication factors and effectiveness of the estimations was tested. The Researchers have been efforting for centuries to find out similarities and differentiation among various human races.

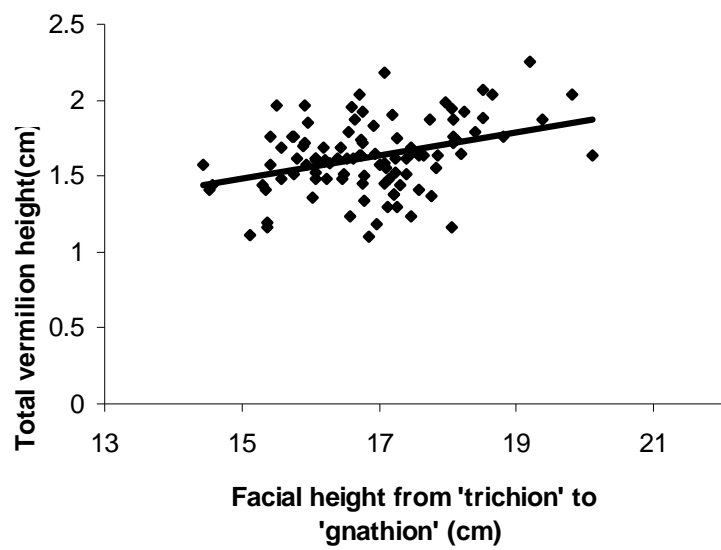

Fig-3: Scatter diagram with regression analysis showing significant positive correlation between the facial height from 'trichion' to 'gnathion' and the total vemilion height. $(\mathrm{r}=0.359, \mathrm{p}=0.001)$.

From their research different unknown information about these variables have been unearth. As Garo tribe belongs to the Mongoloid race, some similarities are expected to exist with other ethnic groups of the Mongoloid race and some dissimilarity may be expected with other races. The mean value of the facial height from 'trichion' to 'gnathion' of the Mongoloid Garo female population was found as $16.88 \mathrm{~cm}$ which is greater than that of a Dangi subcaste ${ }^{\mathbf{1 2}}$ but it is within close limit to that of an Ahirwar subcaste ${ }^{\mathbf{1 2}}$ of India. However it is smaller from some other Caucasoid female population like a North American ${ }^{7}$, an Azerbaijani ${ }^{7}$ and a Czech $^{7}$. It may also be noted that the Garo's mean facial height from 'trichion' to 'gnathion' is greater than that of a Negroid female population like 'Onge' of Little Andaman ${ }^{13}$. The mean nasal length of the Mongoloid Garo female population was found as 
$4.53 \mathrm{~cm}$ which is smaller to that of a Mongoloid Korean American female population ${ }^{14}$ and greater than that of an Austro-Asiartic 'Santhal'15 as well as 'Ahirwar', 12 and Dangi' 12 sub castes of India. On the other hand it is smaller to that of some Caucasoid female populations like a North American $^{7}$, a German ${ }^{7}$ and a Bulgarian ${ }^{7}$. The Garo's mean nasal length is, however greater than that of the studied Negroid females like Onge' of the Little Andaman of India ${ }^{12}$ but it is smaller to that of African American ${ }^{16}$. The mean total vermilion height of the Mongoloid Garo females was found $1.63 \mathrm{~cm}$ which is smaller than that of a Mongoloid Korean American female population ${ }^{17}$ and greater than that of a Mongoloid Chinese female population ${ }^{18}$. This reflects that the Garo's mean total vermilion height vary. It has been found that the value is similar to that found in a population of the Southern part of India ${ }^{19}$. On the other hand the Garo's mean total vermilion height is greater than that of a Caucasian female population ${ }^{19}$ whereas it is smaller to that of a Northern Italian and North American $^{7}$ female population ${ }^{20}$. Facial height from 'trichion' to 'gnathion' was found to have significant positive correlation with the nasal length and total vermilion height. Probably, this is the first such study carried out on the Garo tribal population of Bangladesh and the result of the present study will provide some baseline information regarding such facial measurements of this particular population. No literature available dealing with the possible correlation between the facial height from 'trichion' to 'gnathion' and two other vertical facial dimensions. 'Multiplication factors' were calculated for estimating the facial height from 'trichion' to 'gnathion'. To check whether the multiplication factors could be effective in estimating facial height 'trichion' to 'gnathion' from nasal length and total vermilion height, the 'estimated' values were compared with the 'measured' values. It showed that the 'estimated' values did not differ significantly from the 'measured' values. These findings suggest that multiplication factor for the estimation of these variables might be close to perfect.

Conclusions: The results of this study revealed a clear ethnic variation related anthropometric measurements and these results of the present study will provide some baseline information regarding facial height from 'trichion' to 'gnathion', nasal length, total vermilion height of the Christian Garo adult females. Significant correlations, detected in the study between these measurements can be utilized in the determination of proper multiplication factors to be useful in estimating one measurement from another. This should encourage others in taking up further research in this field.

\section{Acknowledgement}

I would like to express my deepest regards and heartiest gratitude to my honorable guide Professor Jahan Ara Begum, Professor of BSMMU and to my honorable teacher Prof. Khondker Manzare Shamim,
Chairman, department of Anatomy, BSMMU for their enthusiasm, invaluable advice and encouragement in the execution of this work.

\section{References}

1. Omotoso DR, Oludiran OO, Sakpa CL. Nasofacial Anthropometry of Adult Bini Tribe In Nigeria. Afr. J. Biomed. Res. 2011(14); 219 -21.

2. Gray H. Gray's Anatomy. 40th ed. London: Churchill and Livingstone, 2008: 409-21.

3. Krishan K. Anthropometry in Forensic Medicine and Forensic Science-'Forensic Anthropometry'. The Internet Journal of Forensic Sci 2007; 2(1): 18-22

4. Golalipour MJ, Jahanshahi M, Haidari K. The variation of head and face shapes in female newborns in the SouthEast of the Caspian sea (Iran-Gorgan). European Journal Article 2005; 9(2): 95-98.

5. Hennessy RJ, Mclearie S, Kinsella A. Facial surface analysis by 3D laser scanning and geometric morphometrics in relation to sexual dimorphism in cerebral - craniofacial morphogenesis and cognitive function. Journal of Anatomy 2005; 207: 285- 93.

6. Jasuja OP, Singh G. Estimation of stature from hand and phalangeal length. Journal of Indian Academy of Forensic Medicine. 2004;26(3): 100-6.

7. Farkas LG, Katic MJ, Forrest CR, Original article international anthropometric study of facial morphology in various ethnic groups/races. Journal of Craniofacial Surgery $2005 ; 16: 614-22$.

8. Das T, Islam SMHZ. Psychosocial dimensions of ethnicity: the situation of Garo community in Bangladesh. Asian Affairs 2005; 27: 45-54.

9. Ferrario SF, Sforza C, Schmitz JH, Ciusa V, Colombo A. Normal growth and development of the lips; a 3 dimensional study from 6 years to adulthood using a geometric model. Journal of Anatomy 1999;196:415-23.

10. Porter J P. The average African American male face: an anthropometric analysis. Arch Facial Plastic Surgery 2004; 6 (2): 78-81.

11. Krishan K., Kanchan T, Multiplication factor versus regression analysis in stature estimation from hand and foot dimensions. Journal of Forensic and Legal Medicine 2012; 19: 211- 14.

12. Singh P, Purkait R. A cephalometric study among subcaste group Dangi and Ahirwar of Khurai block of Madhya Pradesh Anthropologist 2006; 8: 215-17.

13. Panday AK. Cephalofacial variation among Onges. Anthropologist 2006 ; 8: 245- 49.

14. Choe KS, Yalamanchili HR, Litner JA, Sclafani AP, Quatela V C. The Korean American woman's nose. Facial Plastic Surgery 2006; 8: 319-23.

15. Ghosh S, Malik SL. Sex difference in body size and shape among Santhal of West Bengal. Anthropologist 2007; 9: 143-49.

16. Porter JP, Oslan KL, Anthropometric facial analysis of the African American woman. Arch Facial Plastic Surgery 2001; 3: 191-7.

17. Choe KS, Sclafani AP, Litner JA, Yu GP, Romo, T The Korean American woman's face. Arch Facial Plastic Surgery 2004; 6: 244-52.

18. Du L, Zhuang $\mathrm{Z}$, Guan $\mathrm{H}$ et al. head and face anthropometric survey of Chinese workers. Annals of Occupational Hygiene 2008; 52(8): 773-82.

19. Khandekar B, Srinivasan S, Mokal N, Thatte MR. Anthropometric analysis of lip-nose complex in Indian population. Indian Journal Plastic Surgery 2005; 33(2): 128-31.

20. Ferrario VF, Sforza C, Poggio CE, Schmitz J. Facial volume changes during normal human growth and development. The Anatomical Record 1998; 250:480-87. 